\title{
Non-random distribution of mutations in the PHEX gene, and under-detected missense mutations at non-conserved residues
}

\author{
Denis Filisetti ${ }^{1}$, Georg Ostermann ${ }^{1}$, Moritz von Bredow ${ }^{2}$, Tim Strom ${ }^{3}$, Guido Filler ${ }^{2}$, \\ Johen Ehrich ${ }^{4}$, Solange Pannetier ${ }^{1}$, Jean-Marie Garnier ${ }^{1}$, Peter Rowe ${ }^{5}$, Fiona Francis ${ }^{6}$, \\ Annick Julienne ${ }^{7}$, André Hanauer ${ }^{1}$, Michael J Econs ${ }^{8}$ and Claudine Oudet ${ }^{1}$ \\ ${ }^{1}$ Institut de Génétique et de Biologie Moléculaire et Cellulaire, CNRS, INSERM, ULP, Illkirch, France \\ ${ }^{2}$ Abteilung Kindernephrologie, Universitätsklinik für Kinderheilkunde, Universitätsklinikum Charité, Medizinische \\ Fakultät der Humboldt-Universität zu Berlin \\ ${ }^{3}$ Abteilung Medizinische Genetik, Kinderpoliklinik der Ludwig-Maximilians-Universität, München \\ ${ }^{4}$ Department of Pediatric Nephrology, Orthopedics, Dentistry and Radiology, Medizinische Hochschule, Hannover, \\ Germany \\ ${ }^{5}$ University of London, Royal Free Hospital School of Medicine, Department of Biochemistry and Molecular \\ Biology, London \\ ${ }^{6}$ Institut Cochin de Génétique Moléculaire, INSERM-U129, CHU Cochin Port-Royal, Paris \\ ${ }^{7}$ INSERM-U349, Centre Viggo Petersen, Hôpital Lariboisière, Paris, France \\ ${ }^{8}$ Department of Medicine, Indiana University School of Medicine, Indianapolis, Indiana, USA
}

\begin{abstract}
Thirty newly detected mutations in the $P H E X$ gene are reported, and pooled with all the previously published mutations. The spectrum of mutations displayed $16 \%$ deletions, $8 \%$ insertions, $34 \%$ missense, $27 \%$ nonsense, and $15 \%$ splice site mutations, with two peaks in exon 15, and 17. Since $32.8 \%$ of PHEX amino acids were conserved in the endopeptidases family, the number of missense mutations detected at non-conserved residues was smaller than expected, whereas the number of nonsense mutations observed at non-conserved residues was very close to the expected number. Compared with conserved amino acids, the changes in nonconserved amino acids may result in benign polymorphisms or possibly mild disease that may go undiagnosed.
\end{abstract}

Keywords: X-linked hypophosphataemia; vitamin D resistant rickets; PHEX gene; endopeptidase; HYP phenotype; mutation distribution

Correspondence: Claudine Oudet, IGBMC, 1 rue Laurent Fries, BP163, 67404 Illkirch Cedex, France. Tel: (33) 3886534 14; Fax: (33) 3886532 46; E-mail: coudet@igbmc.ustrasbg.fr

Received 3 December 1998; revised 23 February 1999; accepted 8 March 1999 


\section{Introduction}

Mutations in the PHEX gene (phosphate regulating gene with homologies to endopeptidases on the $\mathbf{X}$ chromosome) have been shown to cause $\mathrm{X}$-linked hypophosphataemic rickets (HYP). ${ }^{1-6}$ Cloning of the human $^{7-9}$ and the mouse ${ }^{7,10-12}$ PHEX cDNA has now been reported by six independent teams.

The gene spans over $220 \mathrm{~kb}$, and is organised into 22 exons; it encodes the PHEX protein, which belongs to the zinc binding endopeptidases family with an amino acid similarity to neutral endopeptidase (NEP) of approximately $60 \%$. The protein has a short 20 amino acid intracytoplasmic tail, a 25 amino acid transmembrane region, and a long 704 amino acid ectodomain. The catalytic site characterising the endopeptidase family is present in exon $17 .^{1-3}$ Consensus motifs containing residues interacting with a putative substrate and the binding zinc site have been identified in exons 15 and 19 respectively. ${ }^{2,3}$

PHEX gene mutations have been demonstrated in up to $83 \%$ of HYP patients. ${ }^{2-6}$ Mutations are large or small deletions, insertions, nonsense, missense, and splice site mutations. No obvious hot spot has been reported, but this can be due to the small number of patients analysed in each study. We show here that the distribution of the detected mutations in the PHEX gene is non-random.

The biological hallmarks of X-linked hypophosphataemic rickets are decreased renal phosphate reabsorption and an inappropriately low calcitriol concentration; affected individuals frequently present with bone pain, short stature, lower limb deformity (from childhood rickets), calcification of the entheses, and tooth abscesses. ${ }^{13-18}$ There are marked variations in disease severity, both between and within families. However, it is not fully understood whether genotype can play a role in severity of phenotype.

\section{Patients and Methods}

Thirty-five clinical records of HYP patients whose mutations in the PHEX gene had been identified, were available, 20 females and 15 males aged from 2 to 75 years were examined. Patients were familial (24) or sporadic (11) cases out of 22 families, and originated from France (16), Germany (14), North Africa (4), and Belgium (1). They gave their informed consent to the inclusion in the study; 24 patients were treated, seven were not, and in four cases, no information was given. Presence (30) or absence (5) of bone deformities were recorded in all patients.

PCR, SSCP, and sequencing of the 22 exons of PHEX were carried out as reported in Rowe et al. ${ }^{2}$

\section{Results and Discussion}

We pooled all the published mutations, ${ }^{1-6}$ except for large deletions spanning more than one exon, and an additional set of 30 mutations we identified recently (Table 1). Altogether, the mutation number amounted to 132; 91 were different mutations, which demonstrates a high incidence of new mutations. In the present study, 22 new mutations are reported. We observed 34\% missense mutations (24 different missenses), $27 \%$ nonsense mutations, and $15 \%$ splice site mutations. The remaining mutations were deletions $(16 \%)$, and insertions $(8 \%)$.

Table 1 Mutations in the $P H E X$ gene

\begin{tabular}{|c|c|c|c|c|c|}
\hline Patient & Case & $\operatorname{Sex}$ & Exon & Mutation & Type \\
\hline FA73 & $\mathrm{Xl}$ & $\mathrm{M}$ & 2 & $\mathrm{gt}>\mathrm{tt}$ & sd \\
\hline EA87 & $\mathrm{sp}$ & $\mathrm{F}$ & 3 & $\mathrm{~T} 242 \mathrm{C}$ & F805 \\
\hline EM84 & $\mathrm{sp}$ & $\mathrm{F}$ & 4 & T413C & $L 138 P$ \\
\hline EG10 & $\mathrm{Xl}$ & $\mathrm{F}$ & 4 & G425C & C142F \\
\hline EL65 & $\mathrm{Xl}$ & $\mathrm{F}$ & 4 & $\mathrm{gt}>\mathrm{ga}$ & sd \\
\hline EM18 & $\mathrm{sp}$ & $\mathrm{F}$ & 6 & A710G & $\mathrm{D} 237 \mathrm{G}$ \\
\hline FM47 & $\mathrm{sp}$ & M & 7 & G832 & E278X \\
\hline EW36 & $\mathrm{sp}$ & $\mathrm{F}$ & 9 & $\mathrm{gt}>\mathrm{gg}$ & sd \\
\hline FA63 & $\mathrm{Xl}$ & M & 11 & 1269delA & fs \\
\hline DR51 & $\mathrm{sp}$ & $\mathrm{F}$ & 12 & G1351T & $\mathrm{E} 451 \mathrm{X}$ \\
\hline ET78 & $\mathrm{sp}$ & $\mathrm{F}$ & 12 & G1363T & $\mathrm{E} 455 \mathrm{X}$ \\
\hline EW77 & $\mathrm{sp}$ & $\mathrm{F}$ & 14 & 1504insGACT & fs \\
\hline DY36 & $\mathrm{sp}$ & M & 14 & del gagt & $s d$ \\
\hline FA70 & $\mathrm{Xl}$ & $\mathrm{F}$ & 15 & G1590C & W520C \\
\hline FA66 & $\mathrm{Xl}$ & M & 15 & $\mathrm{C} 1601 \mathrm{~T}$ & P534L \\
\hline CL73 & $\mathrm{Xl}$ & $\mathrm{F}$ & 15 & $\mathrm{gt}>\mathrm{at}$ & $\mathrm{sd}$ \\
\hline FA67 & $\mathrm{sp}$ & $\mathrm{F}$ & 17 & $\mathrm{C} 1728 \mathrm{~A}$ & A573D \\
\hline EH90 & $\mathrm{sp}$ & $\mathrm{F}$ & 17 & G1736A & G579R \\
\hline EO15 & $\mathrm{Xl}$ & M & 17 & G1736A & G579R \\
\hline FA69 & $\mathrm{Xl}$ & M & 17 & $\mathrm{gt}>$ at & $\mathrm{sd}$ \\
\hline EL27 & $\mathrm{Xl}$ & $\mathrm{F}$ & 19 & G1952C & $R 651 P$ \\
\hline FA68 & $\mathrm{sp}$ & $\mathrm{F}$ & 19 & gt $>$ at & $s d$ \\
\hline EO59 & $\mathrm{sp}$ & $\mathrm{F}$ & 20 & 1986insTGAC & fs \\
\hline EP5 & $\mathrm{sp}$ & M & 20 & T2064A & Y688X \\
\hline CE37 & $\mathrm{sp}$ & M & 21 & $\mathrm{ag}>\mathrm{cg}$ & sa \\
\hline EL50 & $\mathrm{Xl}$ & $\mathrm{F}$ & 21 & 2148delG & fs \\
\hline EA96 & $\mathrm{sp}$ & M & 22 & 2162insCCCT & fs \\
\hline FA72 & $\mathrm{sp}$ & $\mathrm{F}$ & 22 & G2198C & C733S \\
\hline EJ16 & $\mathrm{sp}$ & $\mathrm{F}$ & 22 & C2238G & C746W \\
\hline ET31 & $\mathrm{sp}$ & M & 22 & $\mathrm{C} 2239 \mathrm{~T}$ & $R 747 X$ \\
\hline
\end{tabular}

del: deletion; ins: insertion; fs: frameshift; sa: splice acceptor site; sd: splice donor site; X: stop codon, Xl: X-linked; sp: sporadic. Bold: missense at conserved amino acid in the series of endopeptidases; italic: recurrent mutation. 
The density and nature of mutations are reported in Figure 1. The distribution observed is not random $\left(\chi^{2}=86, P<0.0005\right)$. The number of mutations in the $\mathrm{C}$ terminal half is 1.7 times the number of mutations in the $\mathrm{N}$ terminal half of the protein $\left(\chi^{2}=8.8, P<0.005\right)$, which suggests a more important role for the $\mathrm{C}$ terminal sequence of the protein. In fact, the catalytic site, and two consensus sequences of the endopeptidases family are located in this segment of the protein. Even mutations located at the very $3^{\prime}$ end of the $P H E X$ gene (C746W, R747X, and W749R) are likely to disturb PHEX function.

Although exon 15 and 17 contain only $5.6 \%$ of the cDNA open reading frame, these exons harbour $20 \%$ of the mutations $\left(\chi^{2}=51.6, P<0.0005\right)$. Conversely, exon 5 displays an unexpectedly low number of mutations, when the large size of the exon is taken into account. $20 \%$ of all the reported mutations are recurrent: R20X was observed five times, P534L seven times, G579R eight times (G579V once), and R747X six times. These mutations occurred in familial and sporadic cases of different origin. For example, in the five G579R cases investigated, four different haplotypes were found (not shown).

PHEX contains 10 highly conserved cysteins. ${ }^{1-3}$ We observed six missense mutations in five different cysteins, and three missense mutations leading to new cystein residues. W456C occurred at a highly conserved W, R166C next to a highly conserved W, and W520C concerned a non-conserved residue, and was found at a position where no cystein was observed in the endopeptidases family. New disulphide bonds may be

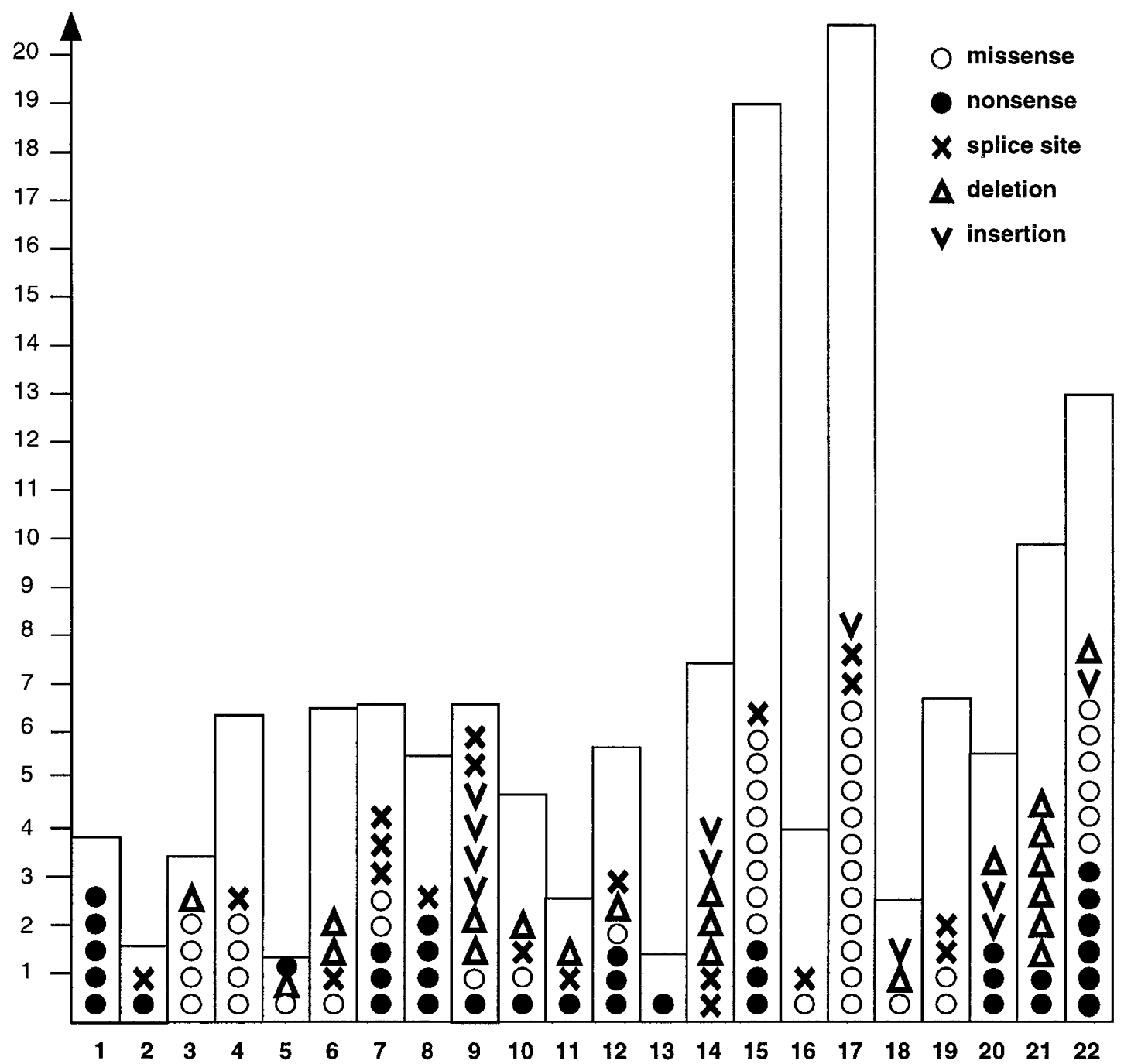

Figure 1 Density of mutations in the 22 exons of the PHEX gene: the density was calculated as $100 \times$ (number of mutations/number of $b p+4)$ of the exon; 2 intronic bp were added to each side of the exon in order to include the mutations in the splice sites. 30 newly detected mutations were pooled with all the previously published mutations. 
generated, disturbing the structural configuration of the protein.

There are $47 \mathrm{CpGs}$ in the $P H E X$ gene; seven are the site of mutations $(17 \%)$ and five were found more than once: R20X (5), R291X (3), P534L (7), R651P (2), R747X (6).

Forty-five missense mutations were detected (Figure 1), among which 24 were distinct mutations. Since conserved residues of the endopeptidases family account for $32.8 \%$ of the whole protein, the expected number of missense mutations would be 14.8 at conserved amino acids, and 30.2 at non-conserved residues. The observed numbers were 39 at conserved residues, and six at non-conserved residues $\left(\chi^{2}=59\right.$, $P<0.0005)$. Missense mutations in non-conserved amino acid of PHEX would thus be five times more frequent than detected. Therefore, either missense mutations occur with a higher frequency in conserved amino acids or there is a greater number of missense mutations generated at non-conserved amino acids that result in benign polymorphisms or lead to a mild phenotype that may go undiagnosed. ${ }^{18}$ Notably, of the 35 nonsense mutations that were observed, 10 occurred at conserved amino acids (11.5 were expected), and 25 mutations occurred in non-conserved residues (23.5 were expected). These values are close to the expected distribution $\left(\chi^{2}=0.28, P>0.05\right)$. Thus it is highly unlikely that missense mutations occur with higher frequency in conserved amino acids compared with non-conserved amino acids. Rather, it is more likely that changes in non-conserved amino acids either do not lead to disease or lead to a mild phenotype that is not detected.

Examination of clinical data of $35 \mathrm{HYP}$ patients carrying 21 different mutations revealed only five individuals (from three families) treated (two females, one male), or not (two females), for the disease, who were reported not to be affected with bone deformities. The mutations segregating in these persons were missense mutations at non-conserved residues, ie D237G, W520C, and R651P. 130 to 170 chromosomes from healthy individuals or from non-mutated $\mathrm{X}$ of hypophosphataemic females were analysed to determine if these changes were rare polymorphisms rather than mutations. Almost all individuals examined were of Caucasian origin. It would be of interest to know whether some patients with the R166C, Y317F, and A720T mutations, whose clinical data were not available, also escaped bone deformities. Only missense mutations are susceptible to maintaining a residual endopeptidase activity (which remains to be experimentally confirmed), and our observations raise the hypothesis that missense mutations at non-conserved residues may contribute, with other factors, to cause a less severe HYP phenotype.

In conclusion, the spectrum of the mutations detected in the PHEX gene shows a higher density in the region including the sequence homologous in the series of endopeptidases. It is possible that changes in non-conserved amino acids more commonly lead to benign polymorphisms or mild disease, that goes undetected.

\section{Acknowledgements}

We thank Drs M Colle, C Guyot, C Heinrichs, E Mallet, M Maumont, M Mathieu for their collaboration; A Staub, I Colas, F Roffenach, E Troesch and S Vicaire for assistance. This study was supported by the Institut National de la Santé et de la Recherche Médicale, the Centre National de la Recherche Scientifique, the Hôpital Universitaire de Strasbourg, and by grants from the Association Française contre les Myopathies, and EC-Biomed BM H4-CT96-0889.

\section{References}

1 The HYP consortium: A gene (PEX) with homologies to endopeptidases is mutated in patients with $\mathrm{X}$-linked hypophosphatemic rickets. Nat Genet 1995; 11: 130-136.

2 Rowe P, Oudet C, Francis F et al: Distribution of mutations in the PEX gene in families with X-linked hypophosphatemic rickets (HYP). Hum Mol Genet 1997; 6: 539-549.

3 Francis F, Ström T, Hennig S et al: Genomic organization of the human PEX gene mutated in X-linked hypophosphatemic rickets. Genome Res 1997; 7: 573-585.

4 Holm I, Huang X, Kunkel L: Mutational analysis of the PEX gene in patients with $\mathrm{X}$ linked hypophosphatemic rickets. Am J Hum Genet 1997; 60: 790-797.

5 Dixon P, Christie P, Wooding C et al: Mutational analysis of PHEX gene in X-linked hypophosphatemia. J Clin Endocrinol Metab 1998; 83: 3615-3623.

6 Rucka A, Tassabehji M, Davies M, Mower E, Read A: X linked hypophosphatemic rickets. Pex gene expression and mutations. Eur J Hum Genet 1998; 6 suppl. 1 P4.240.

7 Beck L, Soumounou Y, Martel J et al: Pex/PEX tissue distribution and evidence for a deletion in the 3 ' region of the Pex gene in X-linked hypophosphatmic mice. J Clin Invest 1997; 99: 1200-1209.

8 Guo R, Quarles D: Cloning and sequencing of human PEX from a bone cDNA library: evidence for its developmental stage-specific regulation in osteoblasts. Am Soc Bone Mineral Res 1997; 127: 1009-1017. 
9 Lipman M, Panda D, Bennett $\mathrm{H}$ et al: Cloning of human PEX cDNA. Expression, subcellular localization, and endopeptidase activity. $J$ Biol Chem 1998; 273: 13729-13737.

$10 \mathrm{Du}$ L, Desbarats M, Viel J, Glorieux F, Cawthorn C, Ecarot B: cDNA cloning of the murine Pex gene implicated in X-linked hypophosphatemia and evidence for expression in bone. Genomics 1996; 36: 22-28.

11 Strom T, Francis F, Lorenz B et al: PEX gene deletions in Gy and Hyp mice provide mouse models for X-linked hypophosphatemia. Hum Mol Genet 1997; 6: 165-171.

12 Grieff M, Whyte M, Thakker R, Mazzarella R: Sequence analysis of $139 \mathrm{~kb}$ in Xp22.1 containing spermine synthase and the 5' region of PEX. Genomics 1997; 44: 227-231.

13 Winters R, Graham J, Williams F, McFalls V, Burnett C: A genetic study of familial hypophosphatemia and vitamin $\mathrm{D}$ resistant rickets with a review of the literature. Medicine 1958; 37: 97-142.
14 Scriver C, Tenenhouse H, Glorieux F: X linked hypophosphatemia: an appreciation of a classic paper and a survey of progress since 1958. Medicine 1991; 70: 218-228.

15 Berndt M, Ehrich J, Lazovic D et al: Clinical course of hypophosphatemic rickets in 23 adults. Clin Nephrol 1996; 45: 33-41.

16 Carpenter T: New perspectives of the biology and treatment of X-linked hypophosphatemic rickets. Pediatr Endocrinol 1997; 44: 443-466.

17 Whyte M, Schranck F, Armamento R: X-linked hypophosphatemia: a search for gender, race, anticipation, or parent of origin effects on disease expression in children. $J$ Endocrinol Metab 1995; 81: 4075-4080.

18 Econs M, Samsa G, Monger M et al: X linked hypophosphatemic rickets: a disease often unknown to affected patients. Bone Mineral 1994; 24 : 17. 